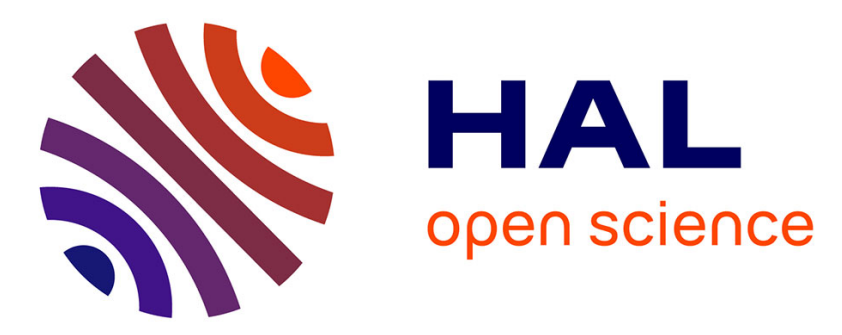

\title{
Dynamic cerebral autoregulatory capacity is affected early in type 2 diabetes mellitus
}

Yu-Sok Kim, Rogier V. Immink, Wim J. Stok, John M. Karemaker, Niels H.

Secher, Johannes J. van Lieshout

\section{- To cite this version:}

Yu-Sok Kim, Rogier V. Immink, Wim J. Stok, John M. Karemaker, Niels H. Secher, et al.. Dynamic cerebral autoregulatory capacity is affected early in type 2 diabetes mellitus. Clinical Science, 2008, 115 (8), pp.255-262. 10.1042/CS20070458 . hal-00479421

\section{HAL Id: hal-00479421 \\ https://hal.science/hal-00479421}

Submitted on 30 Apr 2010

HAL is a multi-disciplinary open access archive for the deposit and dissemination of scientific research documents, whether they are published or not. The documents may come from teaching and research institutions in France or abroad, or from public or private research centers.
L'archive ouverte pluridisciplinaire HAL, est destinée au dépôt et à la diffusion de documents scientifiques de niveau recherche, publiés ou non, émanant des établissements d'enseignement et de recherche français ou étrangers, des laboratoires publics ou privés. 


\title{
Dynamic Cerebral Autoregulatory Capacity is Affected Early in Type 2 Diabetes Mellitus
}

\author{
Y.S. Kim ${ }^{1,4}$, R.V. Immink ${ }^{2,4}$, W.J. Stok ${ }^{3,4}$, J.M. Karemaker ${ }^{3,4}$, \\ N.H. Secher ${ }^{5,6}$ and J.J. van Lieshout ${ }^{1,4}$
}

Department of Internal Medicine ${ }^{1}$, Anesthesiology ${ }^{2}$ and Physiology ${ }^{3}$,

Academic Medical Center, and Human Cardiovascular Physiology Unit, AMC Center for Heart Failure Research ${ }^{4}$, University of Amsterdam, The Netherlands

Department of Anesthesia ${ }^{5}$, The Copenhagen Muscle Research Center ${ }^{6}$, Rigshospitalet, University of Copenhagen, Denmark

Key words: $\quad$ cerebrovascular circulation, diabetes mellitus, diabetes complications, transcranial Doppler, blood pressure

Short title: $\quad$ Cerebral Autoregulation in Type 2 Diabetes Mellitus

Word count: $\quad$ Abstract 246

Main text 3003

Address correspondence to:

J.J. van Lieshout, $\mathrm{MD}, \mathrm{PhD}$

Medium Care Unit, Department of Internal Medicine, F7-205

Academic Medical Center

University of Amsterdam

PO Box 22700, 1100 DE Amsterdam

The Netherlands

tel. (31) 20-5662371

fax (31) 20-5669223

j.j.vanlieshout@amc.uva.nl

Licenced copy. Copying is not permitted, except with prior permission and as allowed by law.

(C) 2008 The Authors Journal compilation (c) 2008 Biochemical Society 


\section{Abstract}

Type 2 diabetes is associated with an increased risk of endothelial dysfunction and microvascular complications with impaired autoregulation of tissue perfusion. Both microvascular disease and cardiovascular autonomic neuropathy may affect cerebral autoregulation. We tested the hypothesis that in absence of cardiovascular autonomic neuropathy, cerebral autoregulation is impaired in subjects with type 2 diabetes with microvascular complications but intact in subjects without complications. Dynamic cerebral autoregulation and the steady state cerebrovascular response to postural change were studied in subjects with type 2 diabetes with $(\mathrm{DM}+)$ and without (DM-) microvascular complications in absence of cardiovascular autonomic neuropathy and in healthy subjects (CTRL). The relationship between spontaneous changes in middle cerebral artery (MCA) blood mean velocity ( $\mathrm{V}_{\text {mean }}$ ) and mean arterial pressure (MAP) was evaluated using frequency domain analysis. In the low frequency region $(0.07-0.15 \mathrm{~Hz})$, the phase lead of the MAP-to-MCA $\mathrm{V}_{\text {mean }}$ transfer function was $52 \pm 10^{\circ}$ in CTRL, reduced in DM- $\left(40 \pm 6^{\circ} ; \mathrm{P}<0.01\right.$ vs. CTRL $)$ and impaired in $\mathrm{DM}+\left(30 \pm 5^{\circ} ; \mathrm{P}<0.01\right.$ vs. $\left.\mathrm{DM}-\right)$ indicating less dampening of blood pressure oscillations by affected dynamic cerebral autoregulation. The steady state response of MCA $\mathrm{V}_{\text {mean }}$ to postural change was comparable for all groups ( $-12 \pm 6 \%$ in CTRL vs. $-15 \pm 6 \%$ in DM- vs. $-15 \pm 7 \%$ in DM+). $\mathrm{HbA}_{1 \mathrm{c}}$ and duration of diabetes but not blood pressure were determinants of transfer function phase. Dysfunction of dynamic cerebral autoregulation in subjects with type 2 diabetes appears to be an early manifestation of microvascular disease prior to the clinical expression of diabetic nephropathy, retinopathy or cardiovascular autonomic neuropathy. 


\section{Introduction}

Blood flow to the brain is influenced by regional changes in neural activity and by global regulatory mechanisms including cerebrovascular autoregulation. Maintenance of cerebral perfusion during physiological challenges is secured by both fast- and slow-acting autoregulatory mechanisms [1]. Although acute changes in arterial blood pressure (ABP) are transmitted to the cerebral circulation, under normal conditions cerebral blood flow (CBF) tends to return to its baseline value within a few seconds [2;3]. This short-term control is usually referred to as dynamic cerebral autoregulation. Static cerebral autoregulation considers the net change in CBF resulting from a manipulated change in cerebral perfusion pressure under steady-state conditions [1-4].

In patients with moderate hypertension, cerebral autoregulation protects the brain from regional hyperperfusion [5]. However, with severe hypertension or ischemic stroke, impairment of cerebral autoregulation leads to loss of control of cerebral perfusion, and CBF becomes a function of arterial pressure, so-called pressure dependency [4;6;7]. Type 2 diabetes is associated with hypertension and an increased risk of endothelial dysfunction and microvascular complications with impaired autoregulation of tissue perfusion [6;8]. In subjects with long-standing type 1 diabetes with orthostatic hypotension due to cardiovascular autonomic neuropathy and microvascular complications including diabetic nephropathy and retinopathy, cerebral autoregulation is impaired [6;9-11]. Impairment of cerebral autoregulation in subjects with diabetes is attributed to both cardiovascular autonomic neuropathy and microvascular endothelial dysfunction associated with cerebral small vessel disease $[6 ; 9 ; 11-13]$. Despite sympathetic innervation of cerebral arteries, the role of the autonomic nervous system in the control of CBF remains controversial.

We hypothesized that in subjects with type 2 diabetes and manifest microvascular complications but without symptomatic cerebrovascular disease, cerebral autoregulatory capacity may become impaired in absence of cardiovascular autonomic neuropathy. We further hypothesized that in subjects with type 2 diabetes who have no signs of microvascular disease or cardiovascular autonomic neuropathy, cerebral autoregulatory capacity is maintained. To test these questions we set out to evaluate the dynamic component of cerebral autoregulatory capacity and the steady state cerebrovascular response to a postural change in subjects with type 2 diabetes and microvascular complications but without symptomatic cerebrovascular disease and cardiovascular autonomic neuropathy $(\mathrm{DM}+)$. Frequency domain analysis evaluated the relationship between transcranial Doppler (TCD) determined beat-to-beat changes in cerebral blood flow velocity (CBFV) and spontaneous ABP oscillations [14;15]. Subjects with type 2 diabetes without microvascular complications (DM-) and healthy control subjects (CTRL) served as reference subjects. 


\section{Methods}

\section{Subjects and study design}

Thirty subjects participated in the study. Ten subjects with complicated type 2 diabetes (DM+, aged $61 \pm 8$ years, 6 male), ten subjects with uncomplicated type 2 diabetes (DM-, aged $54 \pm 8$ years, 5 male) and ten age- and gender matched healthy volunteers (CTRL, aged $61 \pm 16$ years, 4 male) were studied. Each subject received verbal and written information about the study objectives, measurement techniques, and the risks and benefits associated with the investigation. All subjects gave their written informed consent as approved by the AMC Medical Ethical Committee and experiments were performed in accordance with the Declaration of Helsinki. DM+ and DM- subjects had been diagnosed with type 2 diabetes according to the WHO criteria [16] and were receiving treatment with insulin and/or oral antidiabetic agents. Selection criteria for the group DM+ included microvascular complications such as diabetic nephropathy (clinically defined as persistent urinary albumin excretion rate of $>300 \mathrm{mg} / 24 \mathrm{~h}$ or albumin/creatinine ratio $>2.5 \mathrm{mg} / \mathrm{mmol}$ (men) or $>3.5$ $\mathrm{mg} / \mathrm{mmol}$ (women) in the presence of diabetic retinopathy and in the absence of clinical or laboratory evidence of other kidney or renal tract disease) [17;18], retinopathy (diagnosed by an ophthalmologist), and symptoms or signs of diabetic polyneuropathy [19;20]. Subjects without these complications were designated as DM-. Exclusion criteria included history of stroke, TIA, clinical manifestation of cardiovascular disease or heart failure, uncontrolled hypertension (BP >160/100 $\mathrm{mmHg}$ ), orthostatic hypotension, cardiovascular autonomic neuropathy, use of medication with potential influence on autonomic cardiovascular function, and poor metabolic control $\left(\mathrm{HbA}_{1 \mathrm{c}}>\right.$ 9.5\%). Prior to inclusion in the study, all subjects underwent cardiovascular autonomic function testing. Parasympathetic control of heart rate (HR) was evaluated by quantifying time-course and magnitude of HR responses to active standing and the Valsalva maneuver [21-23]. Sympathetic cardiovascular control was assessed by the BP responses to active standing and the Valsalva maneuver [19;24]. The presence of two or more abnormal test results was considered to reflect presence of cardiovascular autonomic neuropathy [19;25]. After a light breakfast, subjects reported to the laboratory at 8:00 a.m. and were studied in a room at $22{ }^{\circ} \mathrm{C}$. They abstained from caffeinated beverages. Subjects were placed in the supine position for instrumentation. After obtaining systemic and cerebrovascular variables in the supine resting position, the subjects were asked to stand up for 5 $\min$.

\section{$A B P, C B F V$ and $P_{E T} C_{2}$}

Continuous ABP was measured non-invasively by a servo-controlled finger photoplethysmograph (Portapres, Finapres Medical Systems, Amsterdam, The Netherlands) with the cuff placed on the middle phalanx of the left middle finger kept at heart level. Changes in mean arterial pressure (MAP) 
measured by photoplethysmography are not different from intra-arterial BP measurements both at rest and during dynamic exercise [26]. An automated non-invasive BP measuring device (HEM705CP, Omron, Kyoto, Japan) was used to calibrate the finger BP measurements. HR was monitored using a lead III ECG. The transcranial Doppler (TCD, DWL Multidop X4, Sipplingen, Germany) derived CBFV was measured in the proximal segment of the right middle cerebral artery (MCA) and insonated through the posterior temporal window. TCD determinations of MCA blood mean velocity $\left(\mathrm{V}_{\text {mean }}\right)$ are reproducible with a difference between two measurements of less than $3 \%$ with $\mathrm{R}=0.95$ [27]. Once the optimal signal-to-noise ratio was obtained, the probe was secured with a headband (Marc 600, Spencer Technologies, Seattle, USA). End-tidal $\mathrm{CO}_{2}$ tension $\left(\mathrm{P}_{\mathrm{ET}} \mathrm{CO}_{2}\right)$ was measured by a sampling infrared capnograph (Tonocap, Datex-Ohmeda, Madison, USA).

\section{Data Analysis}

The signals of BP, spectral envelope of MCA velocity, ECG, and $\mathrm{P}_{\mathrm{ET}} \mathrm{CO}_{2}$ were analog/digital converted at $100 \mathrm{~Hz}$ and stored on a hard disk for off-line analysis, Beat-to-beat values for MCA $\mathrm{V}_{\text {mean }}$ and MAP were derived as the integral over one beat divided by the corresponding beat interval and HR was the inverse of the interbeat pressure interval. MAP at the MCA level was calculated from MAP measured at heart level and the vertical finger-to-TCD probe distance [28]. Cerebrovascular resistance index (CVRi) was the ratio of MAP at brain level ( $\mathrm{MAP}_{\text {brain }}$ ) and MCA $\mathrm{V}_{\text {mean }}$. The Gosling pulsatility index of the MCA was taken as an index of cerebral microangiopathy expressed as the amplitude of CBFV divided by time-averaged CBFV [29].

\section{Cerebral autoregulation}

The steady state response of MCA $\mathrm{V}_{\text {mean }}$ to a postural change in relation to $\mathrm{MAP}_{\text {brain }}$ was assessed from data sampled from $1 \mathrm{~min}$ before and $5 \mathrm{~min}$ after standing. When healthy humans stand up, the head is positioned ca. $30 \mathrm{~cm}$ above heart level within a few seconds, resulting in a reduction in cerebral perfusion pressure of approximately $20 \mathrm{mmHg}$ [15] with a decrease in cerebral tissue

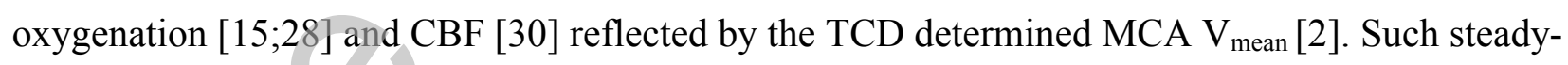
state reductions in cerebral perfusion take place even though the cerebral perfusion pressure remains within what is considered to be its autoregulatory range. In healthy subjects, static cerebral autoregulation limits the physiological reduction in $\mathrm{MCA} \mathrm{V}_{\text {mean }}$ to $\sim 15 \%$ following a postural change $[15 ; 28 ; 31 ; 32]$.

Frequency domain analysis quantified the counter-regulatory capacity of dynamic cerebral autoregulation from spontaneous BP oscillations [3;7]. A 5 min tracing of beat-to-beat data of MAP and MCA $\mathrm{V}_{\text {mean }}$ was spline interpolated and resampled at $4 \mathrm{~Hz}$. To quantify the variability of ABP and CBFV, the power spectra of the two variables were estimated by transforming the time series of $\mathrm{ABP}$ and $\mathrm{CBFV}$ with discrete Fourier transformation to the frequency domain. From the cross 
spectrum, transfer function phase shift and gain were derived. According to the high-pass filter model of cerebral autoregulation, autoregulatory capacity is reflected by the positive phase relation between oscillations of ABP (input function) and CBFV (output function) [3;33]. At high frequencies, less cerebral attenuation of MAP oscillations to MCA $V_{\text {mean }}$ implies that the cerebral autoregulation cannot respond fast enough to rapid changes in MAP [3]. Results were expressed as the averaged integrated area for the low frequency range $(0.07$ to $0.15 \mathrm{~Hz})$. The gain as the ratio of the amplitudes of MCA $\mathrm{V}_{\text {mean }}$ and MAP is taken to reflect the effective amplitude dampening of ABP fluctuations. To examine the strength of the relationship between MAP and MCA $V_{\text {mean }}$, coherence was used to signify that the two cardiovascular signals co-vary significantly in the low frequency area. Like a correlation coefficient, it varies between 0 and 1 , and a coherence above 0.5 was considered to provide a reliable estimate of the transfer function variables. Phase shift was defined positive where MCA $\mathrm{V}_{\text {mean }}$ leads MAP. In healthy subjects, MCA $\mathrm{V}_{\text {mean }}$ leads MAP with $50^{\circ} \sim 60^{\circ}$ in the low frequency range $[3 ; 7]$. To account for the intersubject variability the gain was normalized for MAP and MCA $V_{\text {mean }}$, and expressed as the percentage change in $\mathrm{cm} \cdot \mathrm{s}^{-1}$ per percent change in $\mathrm{mmHg}[3 ; 4]$.

\section{Statistics}

Data are presented as mean $\pm \mathrm{SD}$. When data fitted a normal distribution as indicated by Kolmogorov-Smirnov analysis, an unpaired Student t-test was used and a Mann-Whitney rank sum test was applied when data were not normally distributed. Differences among the 3 groups were identified by ANOVA. A multivariate, stepwise regression model was constructed with MAP-toMCA $V_{\text {mean }}$ transfer function phase as the dependent variable and duration of diabetes, systolic and diastolic BP, BMI, actual plasma glucose and $\mathrm{HbA}_{1 \mathrm{C}}$ as the independent variables, with forward entry and removal. $\mathrm{P}<0.05$ was considered to indicate a statistically significant difference. 


\section{Results}

\section{Subject Characteristics}

Cardiovascular autonomic function test results were without abnormalities. None of the subjects experienced symptoms of orthostatic intolerance or other signs of cerebral hypoperfusion. There were no differences among groups with regard to BMI, age, gender ratio, plasma glucose levels, or systolic and diastolic BP (Table 1). In the DM+ group, duration of diabetes tended to be longer ( $16 \pm 10$ vs. $8 \pm 3$ yr in $\mathrm{DM}$-; $\mathrm{P}=0.14)$ and $\mathrm{HbA}_{1 \mathrm{c}}$ value tended to be higher $(8.0 \pm 1.1 \mathrm{vS}, 7.2 \pm 0.8 \%$ in $\mathrm{DM}-; \mathrm{P}=0.09$ ).

\section{$M C A V_{\text {mean }}$ Response to Postural Change}

At rest prior to standing, baseline cerebro- and cardiovascular variables were comparable between groups, whereas pulsatility index and $\mathrm{P}_{\mathrm{ET}} \mathrm{CO}_{2}$ did not differ (Table 2). With standing, CVRi did not change and the postural reduction in MAP at brain level and in MCA $\mathrm{V}_{\text {mean }}$ was comparable among groups (Fig. 1).

\section{Dynamic Cerebral Autoregulation}

Spectral analysis and MAP-MCA $\mathrm{V}_{\text {mean }}$ transfer function data are given in Table 3 . In the low frequency region (0.07-0.15 Hz), MAP power was lower in both DM- and DM+ compared to CTRL, whereas MCA $\mathrm{V}_{\text {mean }}$ power was comparable between groups. Coherence was $>0.5$ in all groups. The transfer function phase between MAP and MCA $\mathrm{V}_{\text {mean }}$ was $52 \pm 10^{\circ}$ in CTRL, lower in DM- $\left(40 \pm 6^{\circ}\right.$; $\mathrm{P}<0.01$ vs. CTRL) and reduced further in $\mathrm{DM}+\left(30 \pm 5^{\circ} ; \mathrm{P}<0.01\right.$ vs. DM-) (Fig. 2). Phase vs. MAP power did not correlate in the three groups. Representative examples of declining MCA $\mathrm{V}_{\text {mean }}-\mathrm{MAP}$ phase lead are given in Figure 3. The larger gain in DM- and DM+ did not reach statistical significance. Plasma $\mathrm{HbA}_{1 \mathrm{c}}$ and duration of diabetes, but not BMI, plasma glucose, systolic and diastolic BP contributed to a multiple linear regression model of the MAP-to-MCA $\mathrm{V}_{\text {mean }}$ transfer function phase (Table 4). 


\section{Discussion}

The present study provides novel information regarding the dynamic cerebral autoregulation in type 2 diabetes. The major finding was a significant impairment of dynamic cerebral autoregulation in subjects with type 2 diabetes and microvascular complications. This reduced dynamic cerebral autoregulatory capacity was present in absence of signs or symptoms of cardiovascular autonomic neuropathy. Also, in contrast to our hypothesis, dynamic cerebral autoregulatory efficiency was already reduced in subjects with type 2 diabetes in absence of clinical expression of established indicators of microvascular damage. At the same time the steady state response of $M C A V_{\text {mean }}$ to a postural change was unaffected in both DM- and DM+ groups. Together, these findings suggest impairment of dynamic cerebral autoregulation as an early manifestation of microvascular disease prior to cardiovascular autonomic neuropathy or clinical microvascular disease reflected by diabetic nephropathy and retinopathy. The following discussion details the assumptions and evidence that underlie these conclusions.

There are potential limitations of this study that need consideration. The lower age of DM- vs. $\mathrm{DM}+$ questions the effect of age on cerebral autoregulation. However, in healthy subjects ageing does not affect dynamic cerebral autoregulation [34].

The MCA $\mathrm{V}_{\text {mean }}$ was chosen for evaluation of changes in CBF assuming that changes in MCA $\mathrm{V}_{\text {mean }}$ are representative of those in CBF. TCD monitors blood velocity rather than blood flow and changes in the diameter of the insonated vessel by enhanced sympathetic activity could modulate velocity independently of flow. However, large cerebral arteries, including the MCA, are conductance rather than resistance vessels and moderate sympathetic activation does not modify the luminar diameter of a systemic conduit artery [35]. Thus, the constancy of MCA diameter links changes in cerebral blood velocity to changes in flow.

Blood pressure was comparable for CTRL and DM groups. Whereas dynamic and static components of cerebral autoregulatory capacity are affected in malignant hypertension [4], cerebral autoregulation indices are unimpaired in uncomplicated hypertension in middle-aged humans rendering an effect of blood pressure level itself unlikely [36]. In the DM groups an effect of anti-hypertensive medication should be considered. However, integrity of cerebral autoregulation and preservation of $\mathrm{CBF}$ during treatment with beta blockade, calcium channel blocker and angiotensin converting enzyme inhibition or AT1-receptor antagonist are confirmed [37-42]. Thus, hypertensive elderly subjects, whether controlled or uncontrolled with anti-hypertensive medication, retain cerebral autoregulatory capacity [43].

The impairment of dynamic cerebral autoregulation in subjects with type 2 diabetes and microvascular complications in the present study was as severe as what has been found in patients with acute large MCA territory stroke [7]. In patients with unilateral ischemic lacunar stroke, 
dynamic cerebral autoregulation is impaired uniformly at both the non-ischemic and ischemic hemisphere. This is compatible with the notion that pre-existing generalized cerebral small vessel disease may affect cerebral autoregulation [7;11]. MCA $V_{\text {mean }}$ LF power was comparable in all groups, whereas MAP LF power as input to the transfer function was lower in DM- compared to CTRL, and in $\mathrm{DM}+$, the reduction reached statistical significance. This resulted in a higher gain in both DM- and DM+, reflecting proportionally less dampening of MAP oscillations compared to control subjects. Given a lower amplitude of a particular oscillation, there might be more influence of background noise in the determination of oscillation parameters. However, coherence between MAP and MCA $V_{\text {mean }}$ was not statistically different for DM+, DM- and CTRL. Also the expected increase in variance of the extracted parameters, gain and phase, was not observed. Moreover, MAP power and phase did not correlate. Therefore, we consider that the findings do not depend on signal noise, but reflect an inherent problem in DM+. The present study indicates that dynamic cerebral autoregulation becomes affected in subjects with type 2 diabetes prior to the occurrence of cerebral ischemic symptoms.

Impaired cerebral autoregulation is associated with cardiovascular autonomic neuropathy $[11 ; 44]$. Moreover, when healthy humans are subjected to ganglion blockade with development of arterial hypotension, cerebral autoregulation can no longer maintain MCA $\mathrm{V}_{\text {mean }}$ [45]. This has been attributed to removal of vasomotor effects of autonomic neural activity. The present study was designed to account for the influence of cardiovascular autonomic neuropathy by excluding patients with demonstrable cardiovascular autonomic dysfunction by standardized autonomic function tests [19;23]. The mechanism underlying this early decrease in autoregulatory capacity in subjects with type 2 diabetes cannot be determined from the present study, but dynamic cerebral autoregulatory capacity was reduced in absence of overt cardiovascular autonomic neuropathy.

To our knowledge this is the first study to establish a reduction of dynamic cerebral autoregulatory efficiency in subjects with type 2 diabetes who have no clinical evidence of microvascular complications. The cerebral arterial pulsatility index is proposed as an indicator of cerebral microangiopathy in diabetes [29]. An elevated pulsatility index of the MCA in complicated vs. uncomplicated type 2 diabetes and a close correlation with the duration of diabetes suggest that the pulsatility index reflects microangiopathic changes of cerebral vessels [29], but this was not substantiated in the present study where the pulsatility index did not differ across groups. The progressive reduction in phase lead of $\mathrm{MCA} \mathrm{V}_{\text {mean }}$ to MAP correlated closely to the duration of diabetes suggesting that impairment of dynamic cerebral autoregulation is an early marker of microangiopathy in advance of established indicators for retino- and nephropathy.

A role for hyperglycemia regarding affected cerebral autoregulation should be considered. However, in diabetic patients MCA $\mathrm{V}_{\text {mean }}$ does not relate to either glucose or insulin plasma concentrations [46]. Furthermore, hyperglycemic clamping does not affect dynamic cerebral 
autoregulatory capacity both at rest and during exercise [47].

The finding that the physiological postural reduction in MCA $\mathrm{V}_{\text {mean }}$ in both DM- and DM+ was comparable to what is found in healthy subjects confirms the integrity of static cerebral autoregulation [15;32;48]. The present study documents that a reduced dynamic cerebral autoregulatory capacity does not jeopardize cerebral perfusion when exposed to orthostatic stress. The finding that dynamic cerebral autoregulation appears to be a more vulnerable component of cerebrovascular control conforms to earlier observations that progressive impairment in cerebral autoregulation first affects the latency and then the efficiency of the cerebral autoregulation response [1].

Our findings are of concern for subjects with type 2 diabetes who have no clinical evidence for microvascular complications. Subjects with type 2 diabetes are advised to combine aerobic and resistance training [49;50]. Similar to aerobic exercise, resistance training enhances insulin sensitivity but it also involves repeated straining-like maneuvers with abrupt BP increments [31]. The data of this study indicate that transmission of blood pressure surges to the cerebral vasculature is dampened less effectively in subjects with type 2 diabetes. In conclusion, type 2 diabetes is associated with early impairment of dynamic cerebral autoregulation becoming manifest prior to the occurrence of diabetic nephropathy, retinopathy or cardiovascular autonomic neuropathy.

\section{Acknowledgments}

We thank our patients for their cooperation in this study. This study is supported by a grant from the Dutch Diabetes Foundation (Grant \#2004-00-001). 
References

1. Tiecks, F. P., Lam, A. M., Aaslid, R. and Newell, D. W. (1995) Comparison of static and dynamic cerebral autoregulation measurements. Stroke 26, 1014-1019.

2. Aaslid, R., Lindegaard, K. F., Sorteberg, W. and Nornes, H. (1989) Cerebral autoregulation dynamics in humans. Stroke 20, 45-52.

3. Panerai, R. B., Dawson, S. L. and Potter, J. F. (1999) Linear and nonlinear analysis of human dynamic cerebral autoregulation. Am J Physiol Heart Circ Physiol 277, H1089H1099.

4. Immink, R. V., van den Born, B. J., Van Montfrans, G. A., Koopmans, R. P., Karemaker, J. M. and Van Lieshout, J. J. (2004) Impaired cerebral autoregulation in patients with malignant hypertension. Circulation 110, 2241-2245.

5. Lipsitz, L. A., Mukai, S., Hamner, J., Gagnon, M. and Babikian, V. (2000) Dynamic regulation of middle cerebral artery blood flow velocity in aging and hypertension. Stroke 31, 1897-1903.

6. Bentsen, N., Larsen, B. and Lassen, N. A. (1975) Chronically impaired autoregulation of cerebral blood flow in long-term diabetics. Stroke 6, 497-502.

7. Immink, R. V., Van Montfrans, G. A., Stam, J., Karemaker, J. M., Diamant, M. and Van Lieshout, J. J. (2005) Dynamic cerebral autoregulation in acute lacunar and middle cerebral artery territory ischemic stroke. Stroke 36, 2595-2600.

8. Brownlee, M. (2001) Biochemistry and molecular cell biology of diabetic complications. Nature 414, 813-820.

9. Kastrup, J., Rorsgaard, S., Parving, H. H. and Lassen, N. A. (1986) Impaired autoregulation of cerebral blood flow in long-term type I (insulin-dependent) diabetic patients with nephropathy and retinopathy. Clin Physiol 6, 549-559.

10. Albert, S. G., Gomez, C. R., Russell, S., Chaitman, B. R., Bernbaum, M. and Kong, B. A. (1993) Cerebral and ophthalmic artery hemodynamic responses in diabetes mellitus. Diabetes Care 16, 476-482.

11. Mankovsky, B. N., Piolot, R., Mankovsky, O. L. and Ziegler, D. (2003) Impairment of cerebral autoregulation in diabetic patients with cardiovascular autonomic neuropathy and orthostatic hypotension. Diabet. Med 20, 119-126.

12. Hassan, A., Hunt, B. J., O'Sullivan, M. et al. (2003) Markers of endothelial dysfunction in lacunar infarction and ischaemic leukoaraiosis. Brain 126, 424-432.

13. Marthol, H., Brown, C. M., Zikeli, U. et al. (2006) Altered cerebral regulation in type 2 diabetic patients with cardiac autonomic neuropathy. Diabetologia 49, 2481-2487.

14. Panerai, R. B., Eames, P. J. and Potter, J. F. (2003) Variability of time-domain indices of dynamic cerebral autoregulation. Physiol Meas. 24, 367-381. 
15. Van Lieshout, J. J., Wieling, W., Karemaker, J. M. and Secher, N. H. (2003) Syncope, cerebral perfusion, and oxygenation. J Appl Physiol 94, 833-848.

16. American Diabetes Association (2006) Diagnosis and classification of diabetes mellitus. Diabetes Care 29 Suppl 1, S43-S48.

17. Parving, H. H., Gall, M. A., Skott, P. et al. (1992) Prevalence and causes of albuminuria in non-insulin-dependent diabetic patients. Kidney. Int. 41, 758-762.

18. Parving,H.H., Mauer,M. and Ritz,E. (2007) Diabetic Nephropathy. In Brenner \& Rector's The Kidney Saunders, Amsterdam

19. Boulton, A. J., Vinik, A. I., Arezzo, J. C. et al. (2005) Diabetic neuropathies: a statement by the American Diabetes Association. Diabetes Care 28, 956-962.

20. Rosenberg, N. R., Portegies, P., de Visser, M. and Vermeulen, M. (2001) Diagnostic investigation of patients with chronic polyneuropathy: evaluation of a clinical guideline. J. Neurol. Neurosurg. Psychiatry. 71, 205-209.

21. Ewing, D. J. and Clarke, B. F. (1982) Diagnosis and management of diabetic autonomic neuropathy. Br Med J 285, 916-918.

22. Wieling, W., Borst, C., Van Dongen Torman, M. A. et al. (1983) Relationship between impaired parasympathetic and sympathetic cardiovascular control in diabetes mellitus. Diabetologia 24, 422-427.

23. Ten Harkel, A. D. J., Van Lieshout, J. J., Van Lieshout, E. J. and Wieling, W. (1990) Assessment of cardiovascular reflexes: influence of posture and period of preceding rest. J Appl Physiol 68, 147-153

24. Wieling,W. and Van Lieshout,J.J. (1997) Maintenance of postural normotension in humans. In Clinical Autonomic Disorders (Low,P.A., ed.), Little Brown and Company, Boston

25. Ziegler, D. (1994) Diabetic cardiovascular autonomic neuropathy: prognosis, diagnosis and treatment. Diabetes Metab Rev. 10, 339-383.

26. Gizdulich, P., Imholz, B. P. M., van den Meiracker AH, Parati, G. and Wesseling, K. H. (1996) Finapres tracking of systolic pressure and baroreflex sensitivity improved by waveform filtering. J Hypertens. 14, 243-250.

27. Dahl, A., Russell, D., Nyberg Hansen, R. and Rootwelt, K. (1989) Effect of nitroglycerin on cerebral circulation measured by transcranial Doppler and SPECT. Stroke 20, 1733-1736.

28. Harms, M. P. M., Colier, W. N. J. M., Wieling, W., Lenders, J. W., Secher, N. H. and Van Lieshout, J. J. (2000) Orthostatic tolerance, cerebral oxygenation, and blood velocity in humans with sympathetic failure. Stroke 31, 1608-1614.

29. Lee, K. Y., Sohn, Y. H., Baik, J. S., Kim, G. W. and Kim, J. S. (2000) Arterial pulsatility as an index of cerebral microangiopathy in diabetes. Stroke 31, 1111-1115.

30. Scheinberg, P. and Stead, E. A. (1949) The cerebral blood flow in male subjects as measured by the nitrous oxide technique. Normal values for blood flow, oxygen utilization, glucose utilization and peripheral resistance, with observations on the effect of tilting and anxiety. J Clin Invest 28, 1163-1171. 
31. Pott, F., Van Lieshout, J. J., Ide, K., Madsen, P. and Secher, N. H. (2003) Middle cerebral artery blood velocity during intense static exercise is dominated by a Valsalva maneuver. J Appl Physiol 94, 1335-1344.

32. Van Lieshout, J. J., Pott, F., Madsen, P. L., Van Goudoever, J. and Secher, N. H. (2001) Muscle tensing during standing: effects on cerebral tissue oxygenation and cerebral artery blood velocity. Stroke 32, 1546-1551.

33. Diehl, R. R., Linden, D., Lucke, D. and Berlit, P. (1995) Phase relationship between cerebral blood flow velocity and blood pressure. A clinical test of autoregulation. Stroke 26, 1801-1804.

34. Carey, B. J., Eames, P. J., Blake, M. J., Panerai, R. B. and Potter, J. F. (2000) Dynamic cerebral autoregulation is unaffected by aging. Stroke 31, 2895-2900.

35. Panerai, R. B., Dawson, S. L., Eames, P. J. and Potter, J. F. (2001) Cerebral blood flow velocity response to induced and spontaneous sudden changes in arterial blood pressure. Am J Physiol Heart Circ Physiol 280, H2162-H2174.

36. Eames, P. J., Blake, M. J., Panerai, R. B. and Potter, J. F. (2003) Cerebral autoregulation indices are unimpaired by hypertension in middle aged and older people. Am J Hypertens 16, 746-753.

37. Heinke, W., Zysset, S., Hund-Georgiadis, M., Olthoff, D. and von Cramon, D. Y. (2005) The effect of esmolol on cerebral blood flow, cerebral vasoreactivity, and cognitive performance: a functional magnetic resonance imaging study. Anesthesiology 102, 41-50.

38. Waldemar, G., Vorstrup, S., Andersen, A. R., Pedersen, H. and Paulson, O. B. (1989) Angiotensin-converting enzyme inhibition and regional cerebral blood flow in acute stroke. J Cardiovasc Pharmacol 14, 722-729.

39. Estrup, T. M., Paulson, O. B. and Strandgaard, S. (2001) No effect of angiotensin II AT(2)-receptor antagonist PD 123319 on cerebral blood flow autoregulation. J Renin. Angiotensin. Aldosterone. Syst. 2, 188-192.

40. Pandita-Gunawardena, N. D. and Clarke, S. E. (1999) Amlodipine lowers blood pressure without affecting cerebral blood flow as measured by single photon emission computed tomography in elderly hypertensive subjects. Age. Ageing. 28, 451-457.

41. Dyker, A. G., Grosset, D. G. and Lees, K. (1997) Perindopril reduces blood pressure but not cerebral blood flow in patients with recent cerebral ischemic stroke. Stroke 28, $580-583$.

42. Hatazawa, J., Shimosegawa, E., Osaki, Y. et al. (2004) Long-Term AngiotensinConverting Enzyme Inhibitor Perindopril Therapy Improves Cerebral Perfusion Reserve in Patients With Previous Minor Stroke. Stroke.

43. Serrador, J. M., Sorond, F. A., Vyas, M., Gagnon, M., Iloputaife, I. D. and Lipsitz, L. A. (2005) Cerebral pressure-flow relations in hypertensive elderly humans: transfer gain in different frequency domains. J Appl. Physiol 98, 151-159.

44. Chiu, C. C., Yeh, S. J. and Liau.B.Y. (2005) Assessment of cerebral autoregulation in diabetics using time-domain cross-correlation analysis. Journal of Medical and Biological Engineering 25, 53-59. 
45. Zhang, R., Crandall, C. G. and Levine, B. D. (2004) Cerebral hemodynamics during the Valsalva maneuver. Insights from ganglionic blockade. Stroke 35, 843-847.

46. Fulesdi, B., Limburg, M., Bereczki, D. et al. (1999) No relationship between cerebral blood flow velocity and cerebrovascular reserve capacity and contemporaneously measured glucose and insulin concentrations in diabetes mellitus. Acta Diabetol. 36, 191-195.

47. Kim, Y. S., Krogh-Madsen, R., Rasmussen, P. et al. (2007) Effects of hyperglycemia on the cerebrovascular response to rhythmic handgrip exercise. Am J Physiol Heart Circ. Physiol 293, H467-H473.

48. Pott, F., Van Lieshout, J. J., Ide, K., Madsen, P. and Secher, N. H. (2000) Middle cerebral artery blood velocity during a Valsalva maneuver in the standing position. $\mathrm{J}$ Appl Physiol 88, 1545-1550.

49. Sigal, R. J., Kenny, G. P., Wasserman, D. H., Castaneda-Sceppa, C. and White, R. D. (2006) Physical activity/exercise and type 2 diabetes: a consensus statement from the American Diabetes Association. Diabetes Care 29, 1433-1438.

50. Eves, N. D. and Plotnikoff, R. C. (2006) Resistance Training and Type 2 Diabetes: Considerations for implementation at the population level. Diabetes Care 29, 1933-1941. 
Table 1. Subjects Characteristics

\begin{tabular}{|c|c|c|c|}
\hline & \multicolumn{3}{|c|}{ Groups } \\
\hline Characteristic & CTRL & DM- & $\mathrm{DM}+$ \\
\hline Male/female (n) & $4 / 6$ & $5 / 5$ & \\
\hline Age (y) & $61 \pm 16$ & $54 \pm 8$ & $61 \pm 8$ \\
\hline $\operatorname{BMI}\left(\mathrm{kg} / \mathrm{m}^{2}\right)$ & $25.3 \pm 3.6$ & $28.3 \pm 8.1$ & $29.8 \pm 4.0$ \\
\hline Systolic BP (mmHg) & $133 \pm 17$ & $133 \pm 14$ & $137 \pm 13$ \\
\hline Diastolic BP (mmHg) & $74 \pm 11$ & \pm 11 & $76 \pm 7$ \\
\hline Duration of disease $(y)$ & & & $16 \pm 10$ \\
\hline \multicolumn{4}{|l|}{ Microvascular complication: } \\
\hline Retinopathy & & 0 & 6 \\
\hline Nephropathy & & 0 & 6 \\
\hline Polyneuropathy (sensorimotor) & & 0 & 6 \\
\hline Oral hypoglycaemic agents & 0 & 7 & 9 \\
\hline Insulin & & 5 & 8 \\
\hline Plasma glucose (mmol/L) & & $7.5 \pm 1.6$ & $7.5 \pm 1.2$ \\
\hline $\mathrm{HbA}_{1 \mathrm{c}}(\% \mathrm{Hb})$ & & $7.2 \pm 0.8$ & $8.0 \pm 1.1$ \\
\hline Albumin/creatinine ratio $(\mathrm{mg} / \mathrm{mmol})$ & & $0.80 \pm 0.65$ & $8.38 \pm 12.89$ \\
\hline ACE-inhibitor & 0 & 1 & 6 \\
\hline Diuretic & 0 & 4 & 5 \\
\hline ATIIRA & 0 & 1 & 2 \\
\hline$\beta$ blocker & 0 & 2 & 0 \\
\hline Calcium channel blocker & 0 & 2 & 6 \\
\hline Statin & 0 & 5 & 9 \\
\hline
\end{tabular}

No. of abnormal autonomic function tests:

Parasympathetic tests:

- HR response to Valsalva

$\begin{array}{lll}0 & 0 \\ 0 & 0 & 0\end{array}$

- HR response to standing

Sympathetic tests:

- BP response to Valsalva $0 \quad 0$

- BP response to standing

0

$0 \quad 0$

Groups: CTRL, control subjects; DM -, patients without complications; DM +, patients with complications; $\mathrm{BMI}$, body mass index; $\mathrm{BP}$, blood pressure; $\mathrm{HbA}_{1 \mathrm{c}}$, glycosylated hemoglobin; $\mathrm{ACE}$, angiotensin converting enzyme; ATIIRA, angiotensin II receptor antagonist; HR, heart rate. Data are mean \pm SD for 10 subjects per group.

Licenced copy. Copying is not permitted, except with prior permission and as allowed by law. (C) 2008 The Authors Journal compilation (C) 2008 Biochemical Society 
Table 2. Static Cerebral Autoregulation Capacity

Systemic and cerebrovascular hemodynamic variables

\begin{tabular}{|c|c|c|c|c|}
\hline & \multirow{2}{*}{ Group } & \multirow{2}{*}{ Supine } & Standing & \\
\hline & & & $\mathrm{t}=5 \mathrm{~min}$ & \\
\hline \multirow{3}{*}{ MAP heart (mmHg) } & CTRL & $93 \pm 14$ & $102 \pm 18 \ddagger$ & $+6 \%$ \\
\hline & DM - & $94 \pm 12$ & $101 \pm 10 \dagger$ & $+7 \%$ \\
\hline & $\mathrm{DM}+$ & $97 \pm 10$ & $108 \pm 11 t$ & $+11 \%$ \\
\hline \multirow{3}{*}{ MAP brain (mmHg) } & CTRL & & $7=$ & $-18 \%$ \\
\hline & DM - & & & $-19 \%$ \\
\hline & $\mathrm{DM}+$ & & $83 \pm 11 \%$ & $-14 \%$ \\
\hline \multirow{3}{*}{$\operatorname{MCA~} V_{\text {mean }}\left(\mathrm{cm} \cdot \mathrm{s}^{-1}\right)$} & CTRL & $58 \pm 18$ & $51 \pm 17 t$ & $-12 \%$ \\
\hline & DM - & $59 \pm 16$ & $50 \pm 13 \ddagger$ & $-15 \%$ \\
\hline & $\mathrm{DM}+$ & $55 \pm \varepsilon$ & $47 \pm 8$ & $-15 \%$ \\
\hline \multirow{3}{*}{$\mathrm{CVRi}\left(\mathrm{mmHg} \cdot \mathrm{cm}^{-1} \cdot \mathrm{s}^{-1}\right)$} & CTRL & $1.60 \pm 0.42$ & $1.52 \pm 0.62$ & $-5 \%$ \\
\hline & DM & $1.59 \pm 0.42$ & $1.53 \pm 0.56$ & $-4 \%$ \\
\hline & $\mathrm{DM}$ & $1.76 \pm 0.33$ & $1.77 \pm 0.48$ & $0 \%$ \\
\hline \multirow{3}{*}{$\mathrm{ETCO}_{2}(\mathrm{mmHg})$} & CTRL & $42.2 \pm 2.6$ & $39.0 \pm 3.3 \ddagger$ & $-7 \%$ \\
\hline & $\mathrm{DM}$ & $40.6 \pm 2.8$ & $38.1 \pm 2.7+$ & $-6 \%$ \\
\hline & $\mathrm{DM}+$ & $41.2 \pm 2.2$ & $38.9 \pm 2.7+$ & $-6 \%$ \\
\hline \multirow{3}{*}{ Pulsatility Index } & CTRL & $0.93 \pm 0.23$ & & \\
\hline & DM - & $0.87 \pm 0.15$ & & \\
\hline & $\mathrm{DM}+$ & $0.96 \pm 0.23$ & & \\
\hline
\end{tabular}

Groups: CTRL, control subjects; DM -, patients without complications; DM +, with complications; MAP, mean arterial pressure; MCA $\mathrm{V}_{\text {mean, }}$ middle cerebral artery mean cerebral blood flow velocity; $\mathrm{CVRi}$, cerebral vascular resistance index; $\mathrm{ETCO}_{2}$, end-tital $\mathrm{CO}_{2}$; $\dashv \mathrm{P}<0.05$ versus supine, $\ddagger \mathrm{P}<0.01$ versus supine. Values are mean \pm SD for 10 subjects per group. 
Table 3 Dynamic Cerebral Autoregulation Control

Averaged low frequency $(0.07-0.15 \mathrm{~Hz})$ transfer function gain, phase and coherence

\begin{tabular}{|c|c|c|c|}
\hline & CTRL & $\mathrm{DM}-$ & $\mathrm{DM}+$ \\
\hline MAP power $\left(\mathrm{mmHg}^{2} \cdot \mathrm{Hz}^{-1}\right)$ & $9.7 \pm 7.5$ & $4.7 \pm 2.9$ & $3.3 \pm 2.4^{*}$ \\
\hline $\operatorname{MCA~} \mathrm{V}_{\text {mean }}$ power $\left(\left(\mathrm{cm} \cdot \mathrm{s}^{-1}\right)^{2} \cdot \mathrm{Hz}^{-1}\right)$ & $3.5 \pm 2.5$ & $3.8 \pm 3.8$ & \pm 8.6 \\
\hline Coherence $\left(\mathrm{k}^{2}\right)$ & $0.76 \pm 0.11$ & $0.79 \pm 0.12$ & $0.73 \pm 0.12$ \\
\hline Phase (degrees) & $52 \pm 10$ & $40 \pm 6^{* *}$ & $30 \pm 5 * *, \S$ \\
\hline Normalized gain $\left(\% \cdot \%^{-1}\right)$ & $1.21 \pm 0.28$ & $1.47 \pm 0.73$ & $1.44 \pm 0.42$ \\
\hline
\end{tabular}

DM -, patients without complications; $\mathrm{DM}+$, with complications; MAP, mean arterial blood pressure; $\mathrm{MCA} \mathrm{V}_{\text {mean }}$, middle cerebral artery mean blood flow velocity. $* \mathrm{P}<0.05$ versus CTRL, ** $\mathrm{P}<0.01$ versus CTRL, $\S \mathrm{P}<0.01$ versus DM -. Values are mean $\pm \mathrm{SD}$ for 10 subjects. 
Table 4. Stepwise regression analysis of the determinant of transfer function phase in DM+ and DM- subjects

\begin{tabular}{llccc}
\hline In & Variable & SE of estimate & $R^{2}$ Increment & $P$ Value \\
\hline Yes & HbA $_{1 \mathrm{c}}$ & 5.75 & 0.47 & $<0.001$ \\
Yes & Duration of DM & 5.09 & 0.60 & 0.005 \\
No & BMI & & & 0.396 \\
No & BP $_{\text {syst }}$ & & 0.542 \\
No & BP $_{\text {dias }}$ & & 0.639 \\
No & Plasma glucose & & 0.806 \\
\hline
\end{tabular}

In, entering or removal of variables; Yes, variable is in stepwise model; No, variable is not in stepwise regression model; $\mathrm{SE}$, standard error; $\mathrm{BP}_{\text {syst }}$, systolic blood pressure; $\mathrm{BP}_{\text {dias }}$, diastolic blood pressure; 


\section{Figure legends}

\section{Figure 1}

Blood pressure at brain level $\left(\mathrm{MAP}_{\text {brain }}\right)$ and middle cerebral artery mean blood flow velocity (MCA $\mathrm{V}_{\text {mean }}$ ) responses to postural stress in healthy subjects (CTRL $\bigcirc$ ), subjects with uncomplicated $(\mathrm{DM}-\triangle)$ and complicated type 2 diabetes $(\mathrm{DM}+\boldsymbol{\Delta})$. Bar indicates standing.

\section{Figure 2}

Group-averaged low frequency $(0.07-0.15 \mathrm{~Hz})$ transfer function phase between MAP and MCA $\mathrm{V}_{\text {mean }}$ in healthy subjects (CTRL white), subjects with uncomplicated (DM- grey) and complicated (DM+ black) type 2 diabetes. Values are mean \pm SD.

\section{Figure 3}

Representative continuous recordings of blood pressure and cerebral blood flow velocity in a healthy subject (CTRL), in a subject with uncomplicated (DM-) and with complicated type 2 diabetes $(\mathrm{DM}+)$. MCA V, middle cerebral artery blood flow velocity. Note the differences in phase shift between subjects. * Maximum of BP respectively CBFV. 

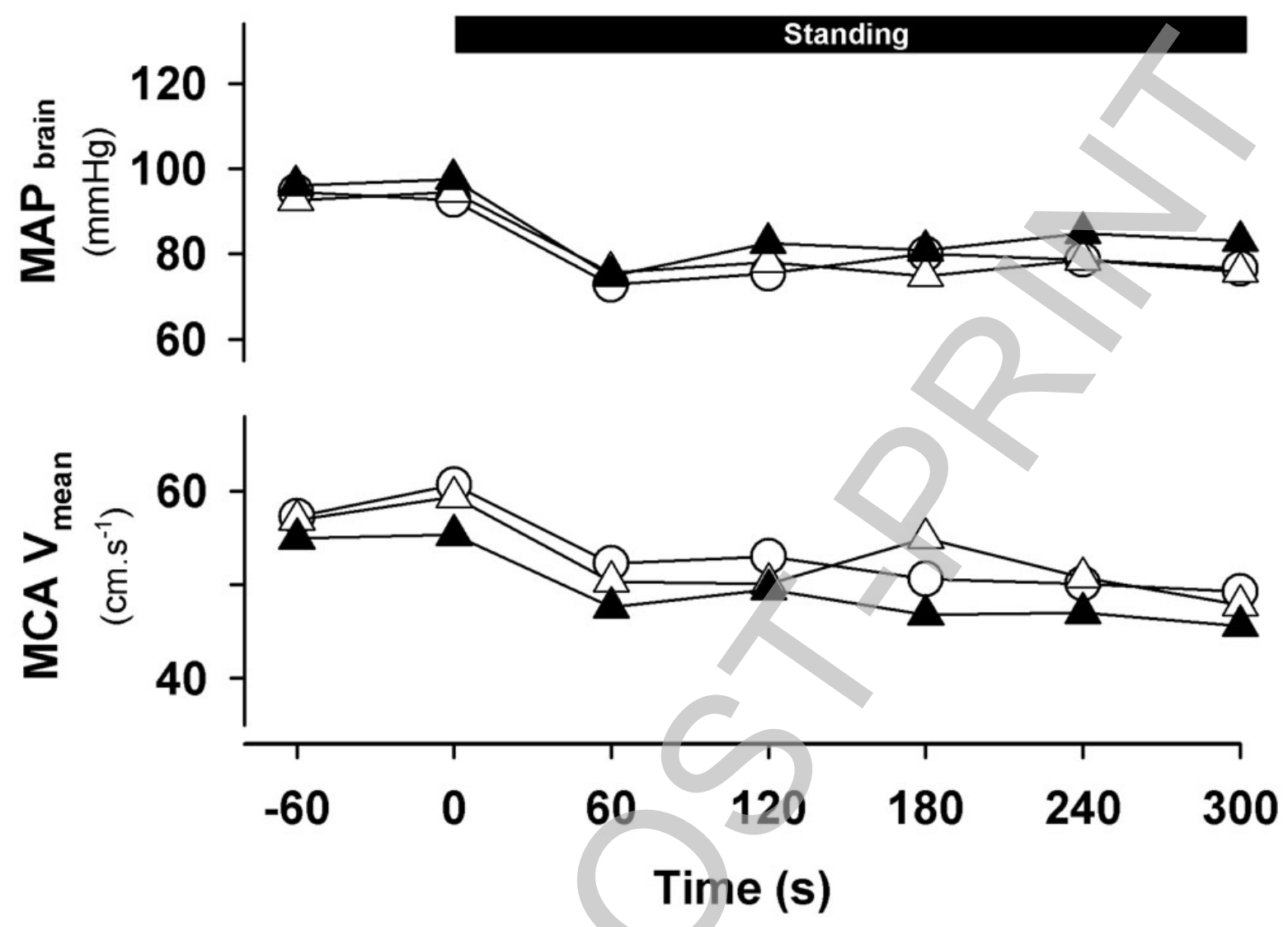

Figure 1 


\section{LF Phase}

(degrees)

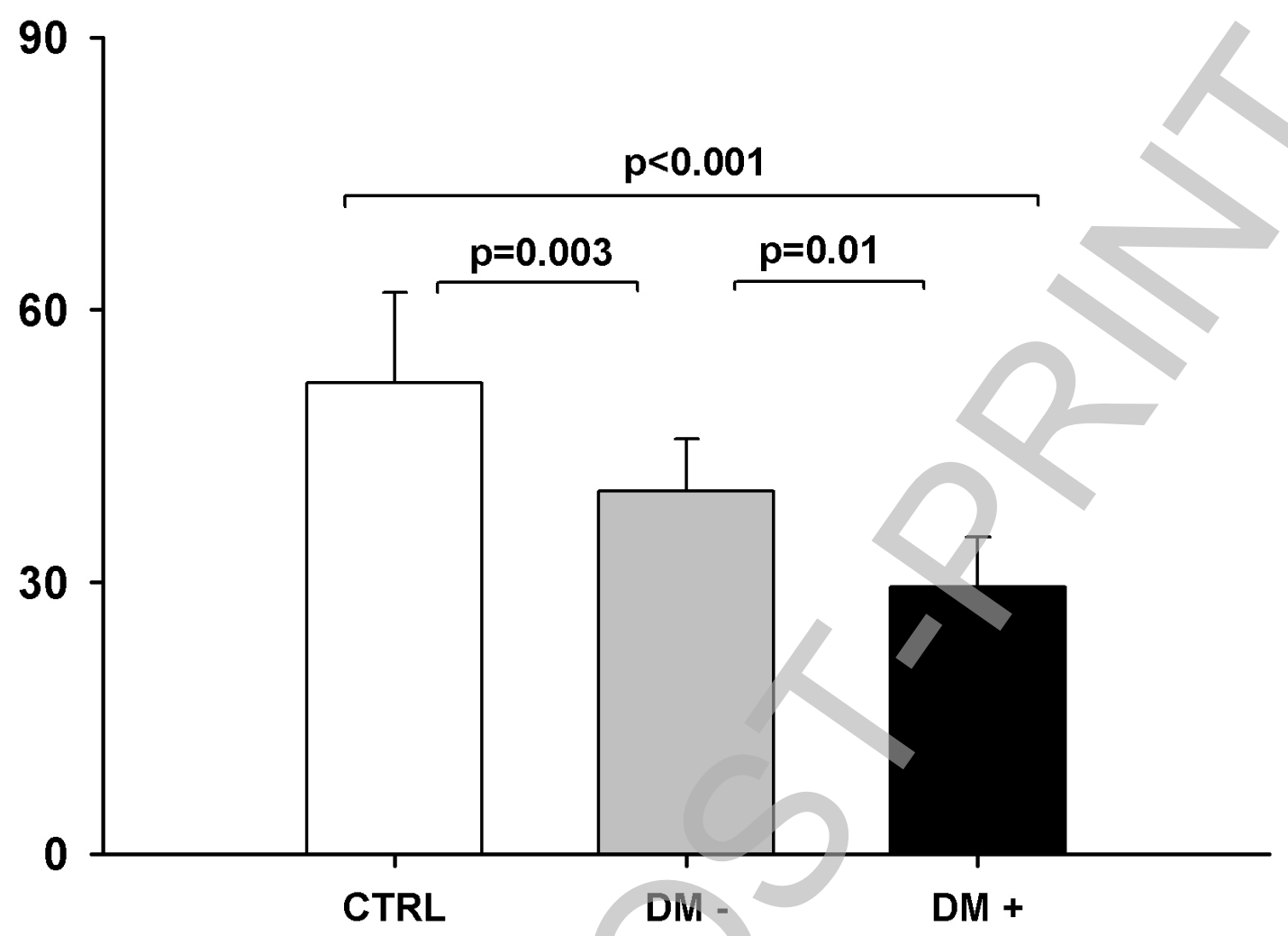

Figure 2 

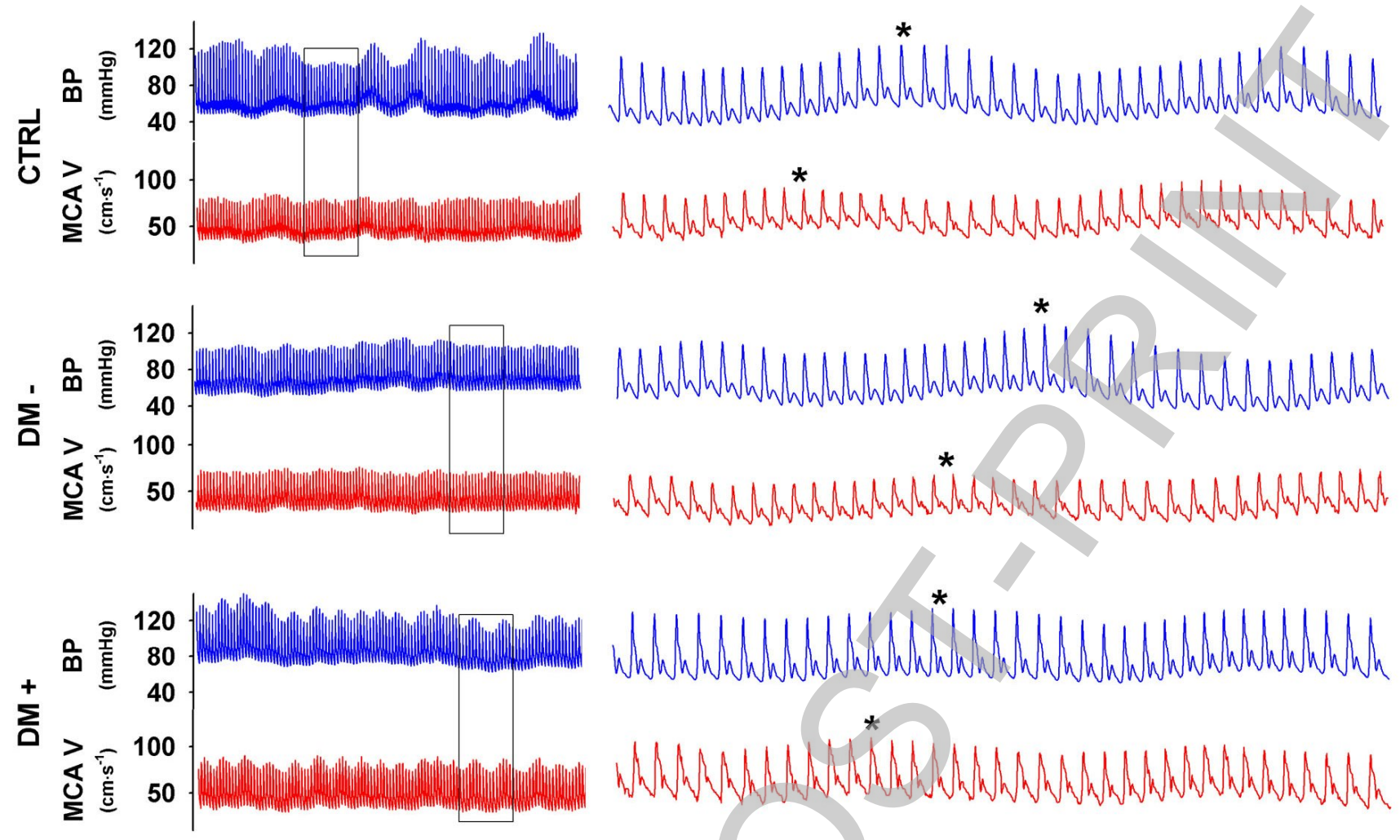

Figure 3

Licenced copy. Copying is not permitted, except with prior permission and as allowed by law. (C) 2008 The Authors Journal compilation (c) 2008 Biochemical Society 